\title{
THE BLOOD SUPPLY OF THE LUMBAR SPINE AND ITS APPLICATION TO THE TECHNIQUE OF INTERTRANSVERSE LUMBAR FUSION
}

\author{
Ian Macnab* and Desmond Dall $\dagger$, Toronto, Canada
}

Intertransverse lumbar fusion has been developed as an alternative technique to posterior or anterior interbody fusion of the lumbar spine. In 1939 Campbell reported a method of placing grafts in contact with the laminae and transverse processes of the fourth and fifth lumbar vertebrae in conjunction with an extra-articular fusion of the sacro-iliac joint. In 1948 Cleveland, Bosworth and Thompson described the use of cancellous grafts placed unilaterally along the bases of the transverse processes and against the posterior joints, as a method of treatment of a pseudarthrosis of a spinal fusion. In 1953 Watkins published a report of a technique using a postero-lateral approach. The spine was approached through an incision lateral to the erector spinae muscle and a cortico-cancellous graft, taken from the crest of the ilium, was attached to the transverse processes by screws. In 1955 Adkins slotted tibial grafts into the transverse processes through a mid-line approach. Since this time many modifications of intertransverse fusion have been described (McElroy 1961; Truchly and Thompson 1962; Wiltse, Batemen and Duey 1962; Curran and McGaw 1968).

It is difficult from a review of the literature to assess the advantages that any one technique has to offer. Cloward (1953) stated that solid bony union was achieved in 98 per cent of interbody fusions; Dommisse (1959) achieved sound bony union in 45 per cent; Adkins (1955), however, reported that only 1.5 per cent of interbody fusions were successful.

Posterior fusion with supplementary screw fixation was reported as being successful in 93 per cent by Boucher (1959), in 84 per cent by Pennal, McDonald and Dale (1964) and in only 45 per cent by Thompson and Ralston (1949). The marked discrepancy in the results observed may arise because there is a significant variation in the underlying pathological lesion and the extent of the fusion. A single segment fusion is more likely to be successful than a three-segment fusion; attempts at refusion of the spine are more prone to failure, and fusion may be more readily achieved in disc degeneration than in spondylolisthesis. In an attempt to assess the value of the technique of intertransverse fusions, these variables have been kept to a minimum.

TABLE I

InCidence of Pseudarthrosis

Two segment fusions (fourth lumbar to first sacral) for degenerative disc disease

\begin{tabular}{|lcc|c|c|}
\hline \multicolumn{1}{|c|}{ Type of operation } & \multicolumn{2}{c|}{ Number of cases } & Pseudarthrosis & Percentage \\
\hline Anterior interbody fusion & 54 & 16 & 30 \\
Posterior fusion &. & 174 & 30 & 17 \\
Intertransverse fusion & 138 & 10 & 7 \\
\hline
\end{tabular}

MATERIAL REVIEWED AND RESULTS

The results obtained by three techniques of spinal fusion were reviewed-anterior interbody fusion, posterior fusion and intertransverse fusion. The technique of posterior fusion consisted of "petalling" of the laminae in the manner described by MacKenzie Forbes

* Chief of Division of Orthopaedic Surgery, Wellesley Hospital, Toronto, Canada.

† Workmen's Compensation Board Research Fellow, Division of Orthopaedic Surgery, Wellesley Hospital, Toronto, Canada. 
(1920) with extra-articular fusion of the posterior joints, supplemented by cancellous bone chips, with or without some form of internal fixation. Although unusual forms of internal fixation were employed on occasions (interspinous ring clamps, plastic plates, Knodt rods and unilateral cold-setting plastic cement), these cases were excluded from the follow-up because they are not in popular use and their inclusion in the series added further variables.

Two types of internal stabilisation were commonly employed: trans-facet screws, and cortico-cancellous slabs wired to the spinous processes. Sometimes the two were combined. The incidence of pseudarthrosis was approximately the same in all the techniques employed, and the results have been considered as a single group-" posterior fusion".

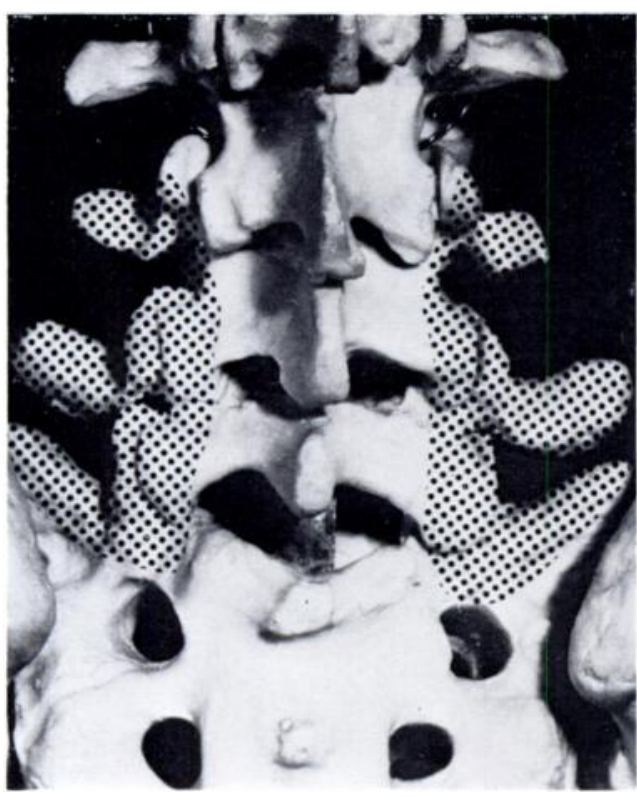

FIG. 1

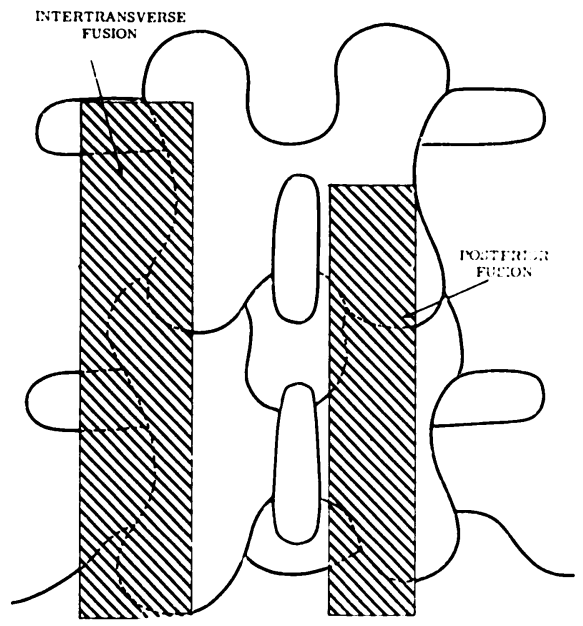

FIG. 2

Figure 1--The shaded zone demarcates the graft bed for an intertransverse fusion. Figure 2 Diagram to compare graft bed of a posterior element fusion and an intertransverse fusion. Note that the graft bed of an intertransverse fusion extends more cranially and includes the pars interarticularis of the most cranial vertebra.

Initially, intertransverse fusions were combined with posterior fusions (thirty-two patients). Subsequently, however, the grafts were never placed medial to the posterior facets. For the purposes of this review these two variations in technique were considered as a single group"intertransverse fusions".

In an endeavour to make the series comparable, the cases reviewed were restricted to two-segment fusions (fourth lumbar to first sacral) undertaken for degenerative disc disease. Patients who were subjected to laminectomy as well as fusion, and patients who had undergone previous operation, were excluded from the review.

Increasing surgical experience is a variable that cannot be excluded, and it is to be noted that early in the series posterior fusion was the only technique employed.

The only result assessed was the achievement of solid fusion. It is notoriously difficult to demonstrate a pseudarthrosis radiologically. A standard technique of "stress films" was employed, using lateral flexion and flexion extension views. Though opportunities for error abound, both in radiological techniques and in measurement, it was felt that such errors would occur with equal frequency in each of the series analysed. An analysis of the results obtained shows that the incidence of pseudarthrosis after intertransverse fusions was significantly lower than in the two other methods employed (Table I). 
There are three reasons that may account for the lower incidence of pseudarthrosis. 1) The graft bed includes the lateral aspect of the superior articular facets, the pars interarticularis and the transverse processes, and as such presents a continuous, uninterrupted,

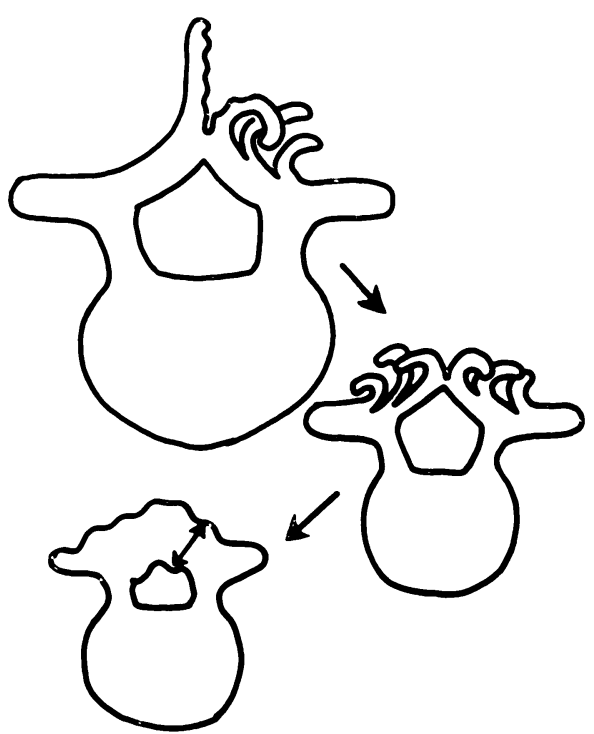

FIG. 3

Diagram to illustrate the thickening of the lamina that sometimes follows the MacKenzie Forbes type of fusion. The thickened lamina decreases the diameter of the spinal canal. raw bony surface to receive the graft and thereby aid revascularisation and reossification (Fig. 1). 2) The zygo-apophysial joints are included in the fusion mass. 3) Because the graft extends to the transverse process of the most cranial vertebra, this vertebral segment is more firmly incorporated in the fusion mass than with the standard posterior technique, in which the graft extends only to the spinous process and lamina of the most cranial vertebra (Fig. 2).

Spondylolysis acquisita-a defect developing in the most cranial segment of the grafted area-has been reported by many authors. This defect was seen in four cases in a series of 380 posterior twosegment and three-segment spinal fusions performed for degenerative disc disease and spondylolisthesis. It was not seen in 260 intertransverse fusions, and theoretically should not occur because the pars interarticularis of the proximal segment is supported by the graft (Fig. 2).

With a MacKenzie Forbes (1920) type of spinal fusion, with decortication of the laminae, with or without the addition of cancellous grafts, the laminae thicken both dorsally and ventrally (Fig. 3). If before fusion there is narrowing of the spinal canal due to a trefoil configuration of the laminae, "shingling" of the laminae, buckling of the ligamentum flavum, or hypertrophic arthritis of the posterior joints, the

TABLE II

BLoOd Loss During Operation

\begin{tabular}{|ccc|}
\hline $\begin{array}{c}\text { Blood loss } \\
\text { (millilitres) } \\
\text { by weighing }\end{array}$ & & Number of cases \\
\hline $100-250$. &. & 16 \\
$250-500$. &. & 69 \\
$500-750$. &. & 17 \\
Over 750. & $\cdot$ & 4 \\
\hline Total . &. & $106 *$ \\
\hline
\end{tabular}

* Blood loss, though weighed, was not recorded in the other cases reviewed.

thickening of the laminae that occurs after a posterior spinal fusion may precipitate the syndrome of spinal stenosis. Symptoms from such a condition have been of sufficient severity to warrant decompression in thirty-four cases. This sequel has not been seen with intertransverse fusions. 
Intertransverse or ala-transverse fusions are of special value in the surgical management of spondylolisthesis where the technique permits stabilisation by a single segment fusion. It is, moreover, the technique of choice for stabilisation of the spine after extensive posterior decompression involving both laminectomy and foraminotomy.

\section{CONTROL OF HAEMORRHAGE}

A serious disadvantage of the technique is that bleeding may be difficult to control and the blood loss incurred may at times be of alarming proportions. Truchly and Thompson (1962) stated: "This is not a simple operation. Because of the vascularity of the operative area, bleeding is a problem; a minimum of one pint of blood, sometimes as many as five pints, was required to replace the blood loss." A knowledge of the vascular anatomy of the lumbar spine, both venous and arterial, permits haemostasis to be maintained throughout the procedure

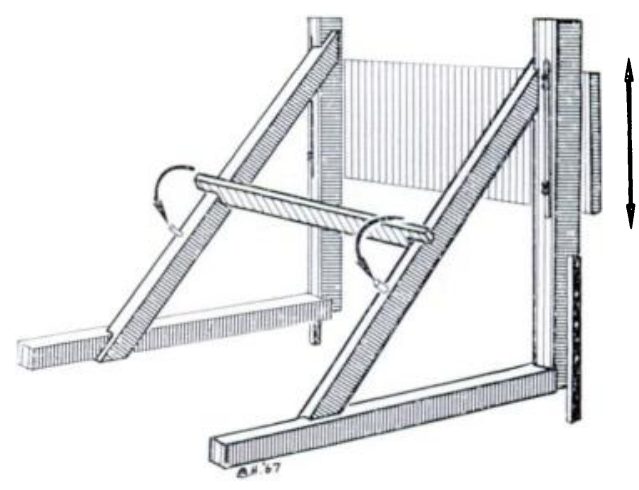

Fig. 4

The Hastings frame. The frame fits on to the side rails of a standard operating room table. The buttock rest is adjustable in height. The cross brace is removable to permit alteration of the position of the legs after the patient has been placed on the frame. and keeps the loss of blood to a minimum (Table II).

The first prerequisite to minimise blood loss is to avoid congestion of the paravertebral venous plexus. The peritoneum is a sac and any pressure on it, from the front, or even from the side, may obstruct the vena cava and divert venous return from the lower limbs through

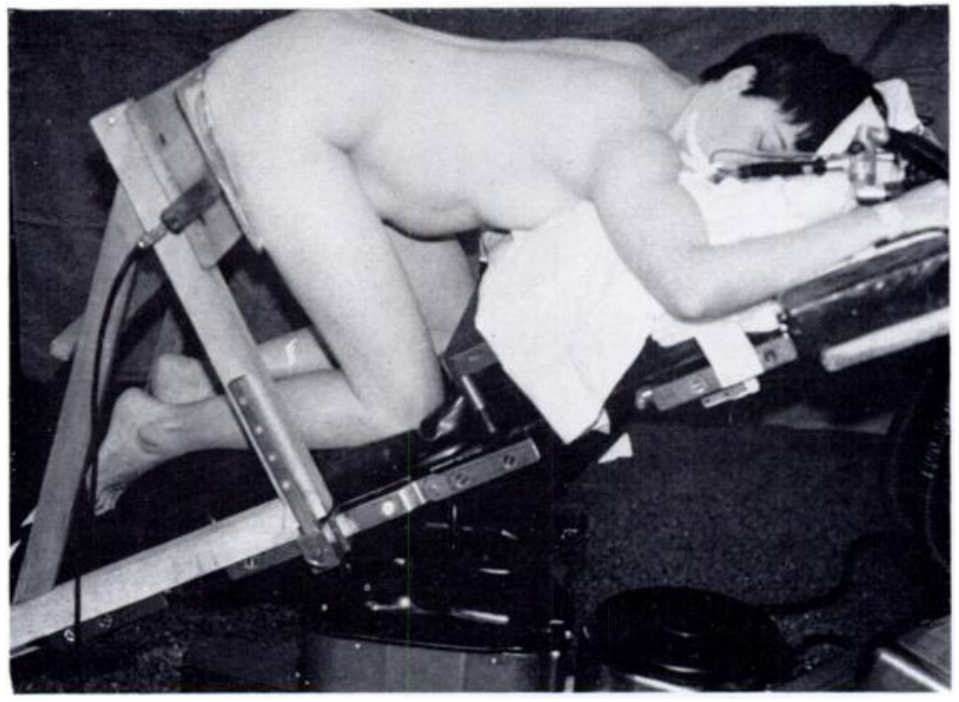

FIG. 5

The Hastings frame permits the hips and knees to be maintained at right-angle flexion. This obviates two problems associated with the knee-chest positionfull flexion of the knees compressing the popliteal veins, and pressure on the abdomen by the thighs. The abdomen is completely free.

Batson's plexus (Batson 1940). Relton and Hall (1967) and Laurin, Migneault, Brunet and Roy (1969) demonstrated obstruction of the vena cava in patients lying prone with the abdomen supported by bolsters and by commercially available spinal frames. Although the knee-chest position decreases abdominal compression to some degree, it increases the hazard of 
thrombophlebitis. A modified knee-chest position with the buttocks supported by a simple frame (Fig. 4), such as that designed by Hastings (1969), keeps the knees flexed at a right angle and takes all the pressure away from the abdomen (Fig. 5). This positioning of the patient allows blood to flow from Batson's plexus into the vena cava and, by itself, markedly decreases the blood loss during the initial phases of the exposure. Total curarisation with positive pressure ventilation decreases venous stasis and greatly facilitates muscle stripping and retraction.

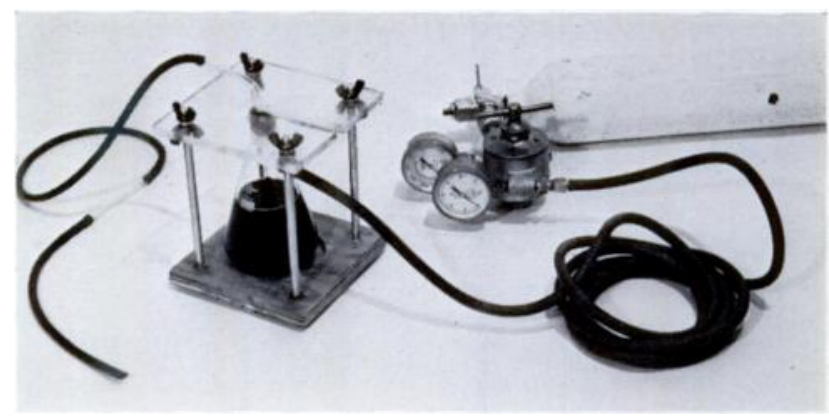

Fig. 6

Apparatus used to inject Tensol 7 cement: oxygen cylinder with reducing valves; Wolff bottle with clamp to maintain position of stopper.

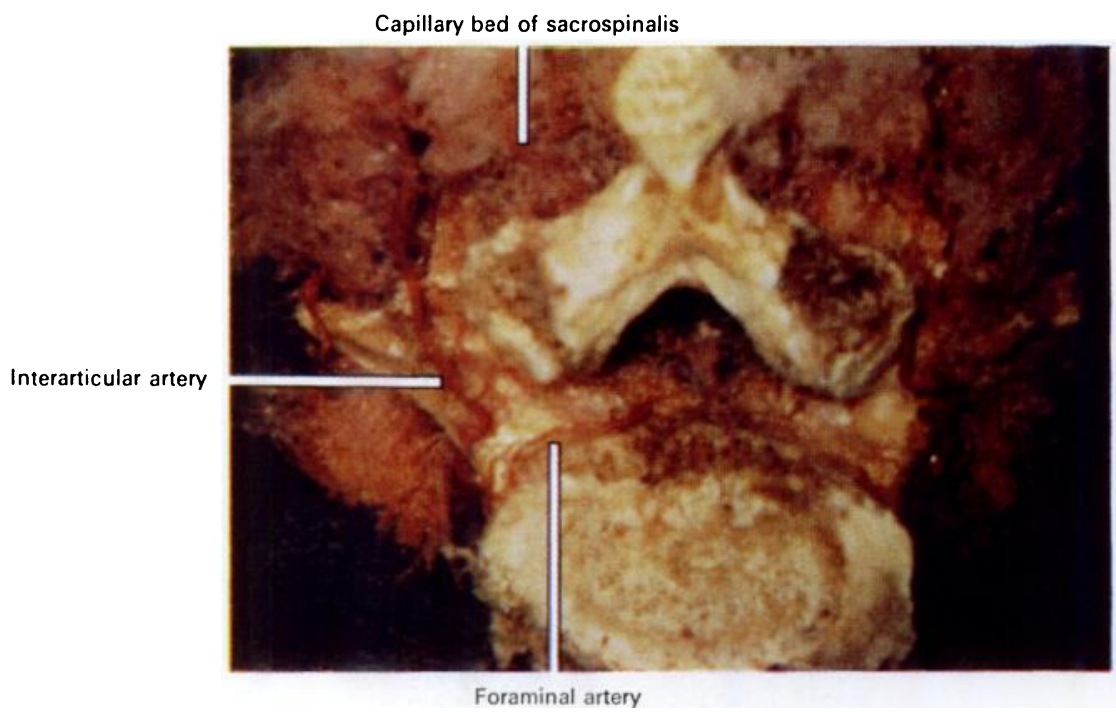

FIG. 7

Injected specimen after corrosion and before dissection of capillary network.

The second major source of bleeding occurs from a disruption of the para-articular vessels. Though these vessels are remarkably constant, their anatomical distribution in the human lumbar spine has not been previously described. In this study these vessels were demonstrated by the corrosion casting technique as described by Bugge (1963).

\section{EXPERIMENTAL METHOD}

A cold setting methylmethacrylate polymer (Tensol cement No. 7), coloured with a red plastic dye, was injected into the distal thoracic aorta in fresh cadavers after ligation of the 
common iliac arteries and visceral branches of the abdominal aorta. The Tensol cement mixed with an activator was injected under constant pressure of one atmosphere (Fig. 6) by

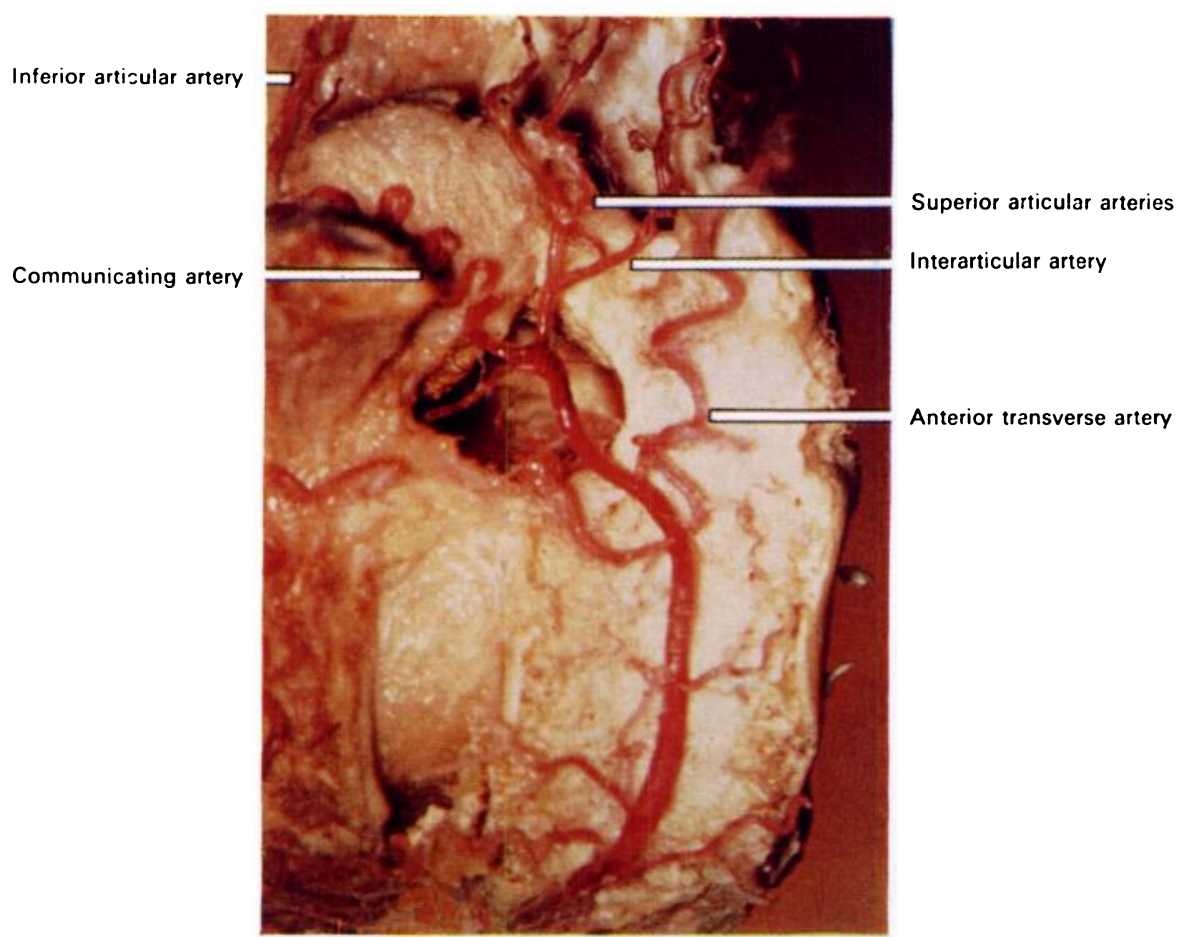

FIG. 8

Injected specimen to show disposition of the major muscular branches of a lumbar artery.

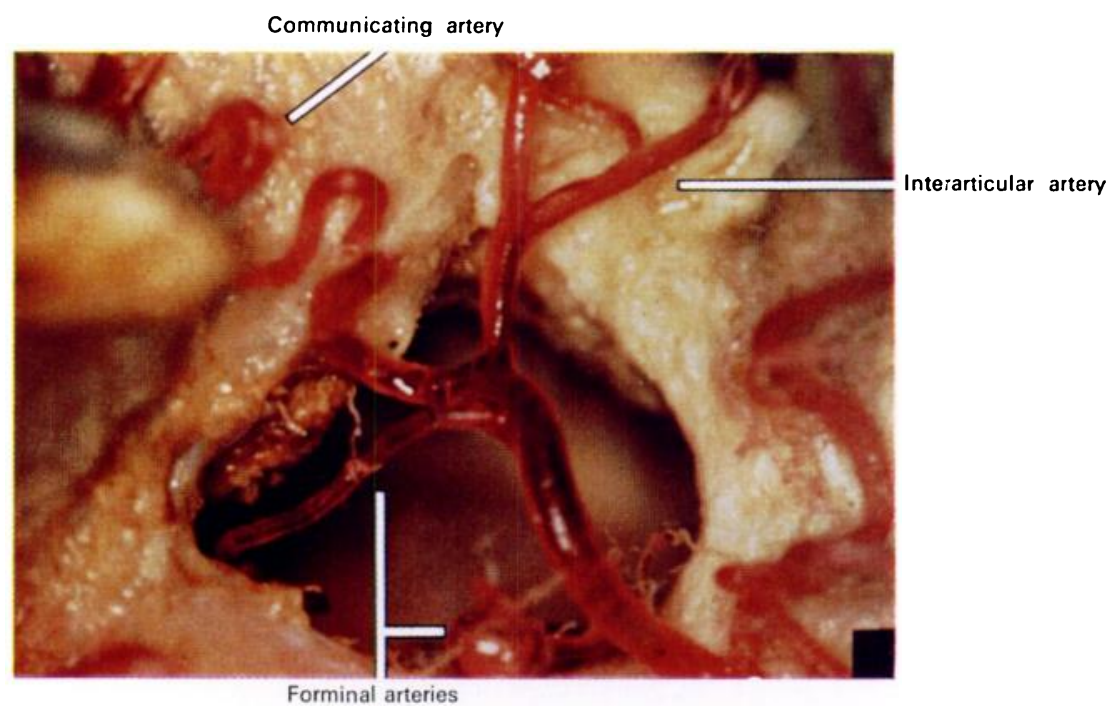

FiG. 9

Injected specimen showing small, but constant vessels entering the intervertebral foramen.

the technique described by Summersmith (1969). Three segments of the lumbar spine were then excised, stored for twenty-four hours to allow complete polymerisation, and then VOL. 53 B, NO. 4, NOVEMBER 1971 
immersed in 10 per cent potassium hydroxide for eight hours to corrode the soft tissues. The specimens were then washed in flowing water for twenty-four hours. The cycle had to te repeated three to six times to achieve complete destruction of all soft tissues and unhampered demonstration of the para-articular branches of the lumbar arteries. Minute muscle vessels were filled by this technique and the sacrospinalis and the psoas muscles resembled candy-floss (Fig. 7). This capillary network had to te dissected away carefully to demonstrate surgically significant arteries.

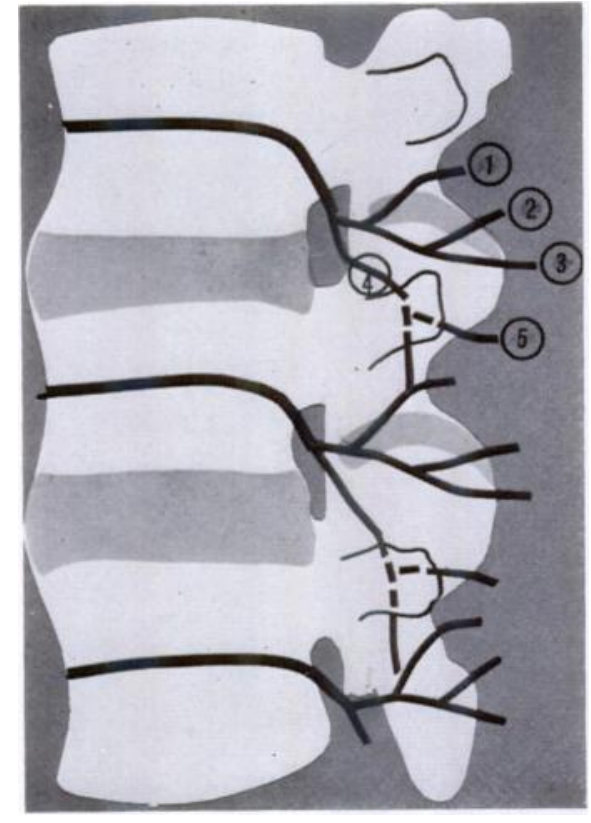

FIG. 10

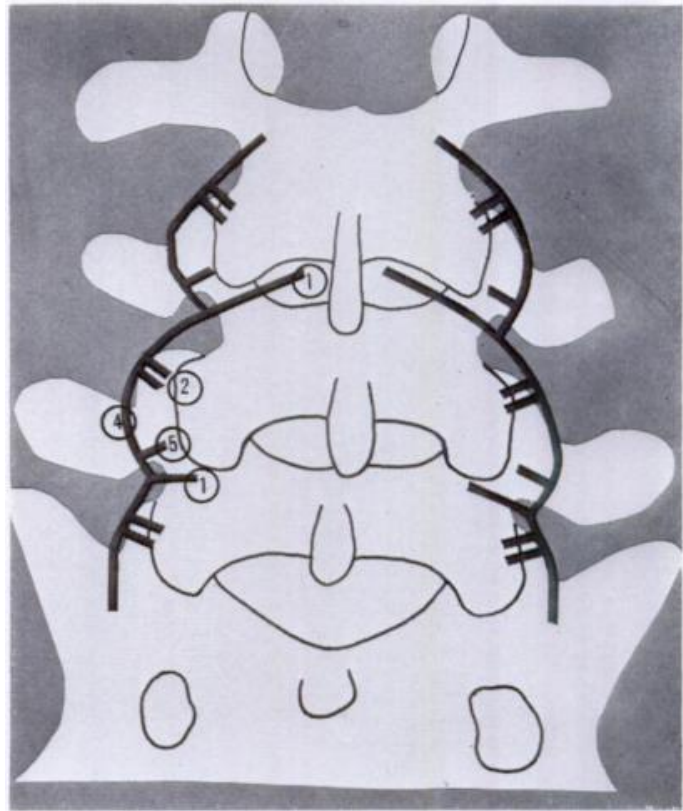

Fig. 11

Figure 10 Diagram to show the disposition of the major muscular branches of the lumbar arteries. 1) Interarticular artery: 2 and 3) superior articular arteries: 4) communicating branch: 5) Inferior articular artery. Figure 11-Diagram to show the disposition of the muscular branches of the lumbar arteries in relation to the operative exposure. The interarticular artery (1) is found immediately lateral to the pars interarticularis. The two superior articular arteries (2) lie immediately lateral to the tip of the superior articular facet. The inferior articular artery (5) lies in the angle formed by the transverse process and the superior articular facet. The communicating artery (4) is a large vessel lying immediately lateral to the superior articular facet on the dorsal surface of the transverse process.

\section{OBSERVATIONS}

Each lumbar artery, as it passes round the lateral aspect of the vertebral body, gives off an antero-lateral intraosseous branch (Ferguson 1950) and muscular branches to the psoas including a very large branch which runs on the anterior surface of the transverse process. The main trunk then reaches the interval between the adjacent transverse processes and divides into several branches.

A dorsal branch is given off opposite the intervertebral foramen. It divides almost immediately into spinal and muscular branches. The divisions of the spinal branch have been described previously by Ferguson (1950) and Epstein (1962). They described: 1) a post-central branch to the vertebral arches and ligamentum flavum;2) anterior and posterior radicular branches to supply the nerve roots, cauda equina and meninges; 3) a dorso-medial branch supplying the posterior longitudinal ligament and posterior aspect of the vertebral body; and 4) muscular branches.

The last are the vessels frequently encountered at operation and these have not been previously described in detail (Figs. 8 and 9). 
The interarticular artery-This artery passes along the lateral aspect of the pars interarticularis, curving medially over its posterior surface. It then passes into the fibro-fatty tissue at the

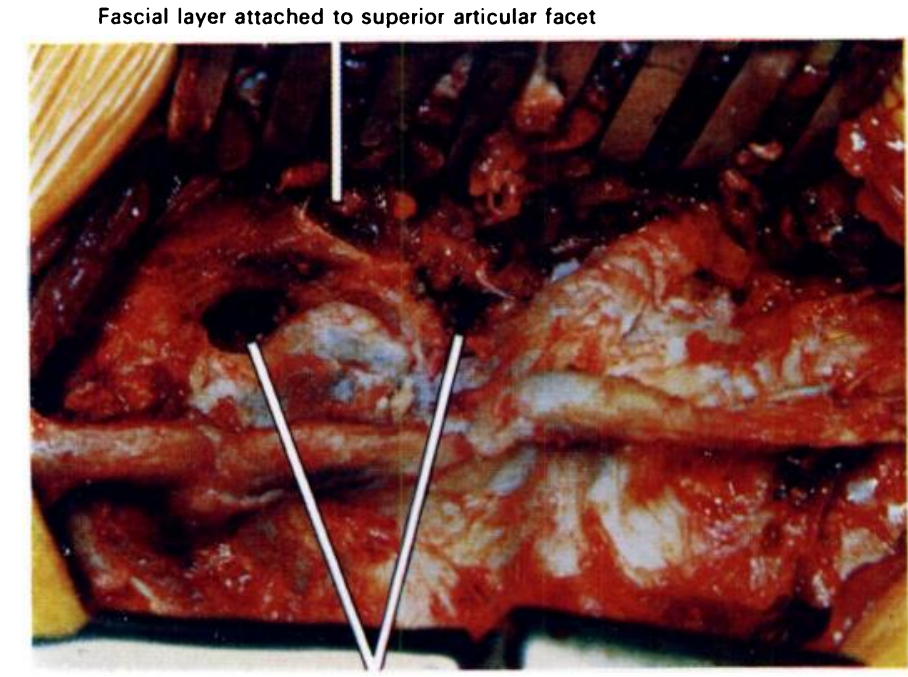

Cauterised interarticular arteries

FIG. 12

Operative photograph of exposure employed. The interarticular arteries have been cauterised as they curve round the isthmus. The intermediate layer of fascia is clearly demonstrated attached to the superior articular facet of the fifth lumbar vertebra.

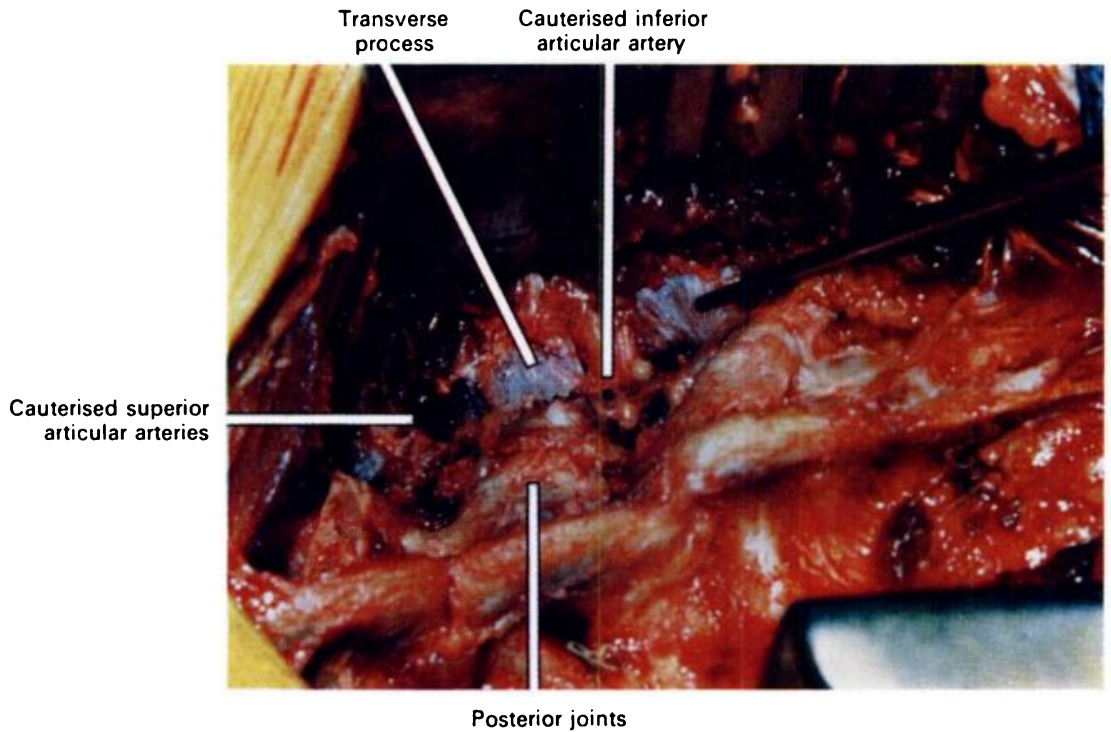

Fig. 13

Operative exposure. The muscular branches have been cauterised and the transverse processes clearly exposed.

lateral aspect of the ligamentum flavum. From here it may pass more medially towards the spinous process and then curve sharply posteriorly into the sacrospinalis muscle mass, or it may pass directly posteriorly from the fibro-fatty tissue into the sacrospinalis.

VOL. 53 B, NO. 4, NOVEMBER 1971 
Superior articular arteries-There are usually two arteries curving posteriorly around the supero-lateral aspect of the posterior joints. These arteries usually pierce a layer of fascia passing laterally from the joint capsule. Standard anatomy texts make no reference to this fascia, but it has been found to be a constant anatomical feature at operation. It forms an intermediate layer ketween the posterior and middle layers of the lumbar fascia. It arises from the posterior joint capsules and, passing laterally, blends with the deep fascia separating the various portions of the sacrospinalis complex.

The communicating artery-This is often a large vessel. It adopts a tortuous course over the posterior aspect of the transverse process usually between the mamillary process and the posterior joint. It communicates with the interarticular branch of the lumbar artery supplying the segment kelow. This artery usually gives off an inferior articular branch.

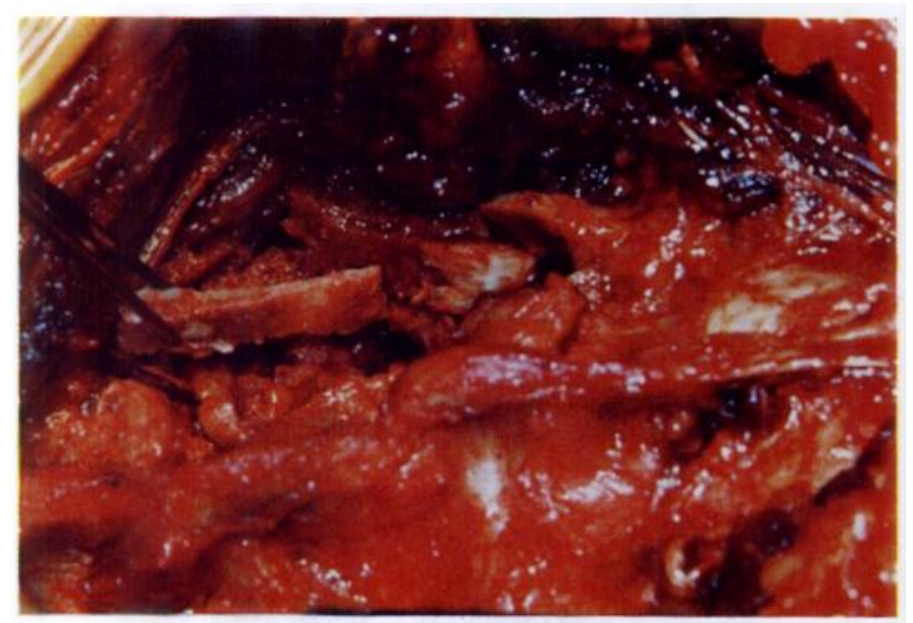

FIG. 14

Bone slivers packed into the para-articular gutter on the lateral surface of the articular facets.

Foraminal arteries-- Two constant branches are given off as the lumbar artery passes across the intervertebral foramen. These supply the structures in the neural canal and the posterior portions of the vertebral body.

The inferior articular artery-This artery is given off by the communicating artery of the segment above or, on occasions, by the interarticular branch of the segment below. It is constant in position. It curves posteriorly around the infero-lateral aspect of the joints and pierces the intermediate layer of the lumbar fascia described above.

The intertransverse artery--At the point of division of the dorsal branch of the lumbar artery a very large artery is given off which passes laterally along the anterior surface of the middle layer of the lumbar fascia, approximately midway between the transverse processes of adjacent segments.

The anterior transwerse artery-This is a relatively large vessel. It arises from the main trunk of the lumbar artery and courses along the anterior surface of the transverse process.

\section{SURGICAL APPLICATION}

Though numerous small muscular and osseous branches are given off, the main branches mentioned above were found to be remarkably constant in their anatomical distribution (Figs. 10 and 11). A knowledge of the disposition of these articular and muscular branches of the lumbar arteries makes it possible, in many instances, to identify and cauterise the vessels before dividing them or, when ruptured accidentally, to find the source of bleeding rapidly. 
To control these vessels they must be sought specifically. The muscles are stripped from the spine and the laminae out to the posterior joints, and are firmly retracted with a rigid self-retaining retractor. Firm retraction clearly demonstrates the intermediate layer of the lumbar fascia which is attached to the posterior border of the superior articular facets and the pars interarticularis (Fig. 12). The muscular and articular branches of the lumbar arteries lie immediately behind this fascial plane. The fascia, which is thin, should first be incised carefully along the dorsal edge of one superior articular facet. When this is done the superior and inferior articular branches can be identified and cauterised. The base of the transverse process is now exposed with a periosteal elevator, and the communicating artery can be seen at the junction of the inferior border of the transverse process with the pars interarticularis. The interarticular artery can next be identified, lying immediately lateral to the mid portion of the pars interarticularis. With these vessels cauterised, the dissection usually can be extended to the tips of the transverse processes without further bleeding (Fig. 13).

The bed for the graft can now be prepared by decorticating the lateral aspect of the superior articular facets, the pars interarticularis and the inferior borders of the transverse processes. Cancellous bone chips are placed in this para-articular gutter (Fig. 14) and the intertransverse graft supplemented by cancellous bone packed around the posterior joints after decortication of the inferior facets.

Dissection should not be carried on to the anterior surface of the transverse process. This does not significantly enhance the fusion bed, and the bleeding that results from rupture of the anterior transverse artery is profuse and difficult to control. If inadvertently divided, the artery can be cauterised by compressing it against the transverse process with a blunt dural hook. Similarly, it is inadvisable to develop a plane of dissection between the transverse processes anterior to the intertransverse muscles. The large intertransverse vessels lie in this plane and retract deeply into the wound when divided. Bleeding from these vessels may result in a significant retroperitoneal haematoma, giving rise to a troublesome ileus in the postoperative period.

\section{SUMMARY}

1. Intertransverse fusion in the lumbar spine appears to have many advantages over previously described techniques.

2. The disadvantage of profuse bleeding can be overcome by the use of a Hastings frame and by an operative technique designed to demonstrate constant muscular and articular branches of the lumbar arteries.

3. Coagulation of these vessels by cautery and avoidance of dissection anterior to the plane of the transverse processes ensure that the operative procedure can be carried out with a blood loss averaging less than 500 millilitres.

This work was supported by a grant awarded by the Workmen's Compensation Board of Ontario.

\section{REFERENCES}

AdKins, E. W. O. (1955): Lumbo-sacral Arthrodesis after Laminectomy. Journal of Bone and Joint Surgery, 37-B, 208.

Batson, O. V. (1940): The Function of the Vertebral Veins and their Rôle in the Spread of Metastases. Annals of Surgery, 112, 138.

Boucher, H. H. (1959): A Method of Spinal Fusion. Journal of Bone and Joint Surgery, 41-B, 248.

Bugge, J. (1963): A Standardized Plastic Injection Technique for Anatomical Purposes. Acta Anatomica, 54, 177.

Campbel., W. C. (1939): Operative Orthopedics. St Louis, Missouri: C. V. Mosby Company.

Cleveland, M., Bosworth, D. M., and Thompson, F. R. (1948): Pseudarthrosis in the Lumbosacral Spine. Journal of Bone and Joint Surgery, 30-A, 302.

Cloward, R. B. (1953): The Treatment of Ruptured Lumbar Intervertebral Discs by Vertebral Body Fusion. Journal of Neurosurgery, 10, 154.

VOL. 53 B, NO. 4, NOVEMBER 1971

$\mathrm{E}$ 
Curran, J. P., and McGaw, W. H. (1968): Posterolateral Spinal Fusion with Pedicle Grafts. Clinical Orthopaedics and Related Research, 59, 125.

Doмmisse, G. F. (1959): Lumbo-sacral Inter-body Spinal Fusion. Journal of Bone and Joint Surgery, $41-B, 87$.

Epstein, B. S. (1962): The Spine. A Radiological Text and Atlas. Second edition, p. 33. Philadelphia: Lea and Febiger.

Ferguson, W. R. (1950): Some Observations on the Circulation in Foetal and Infant Spines. Journal of Bone and Joint Surgery, 32-A, 640.

Forbes, A. M.(1920): Technique of an Operation for Spinal Fusion as Practised in Montreal. Journal of Orthopaedic Surgery, 2, 509.

Harmon, P. H. (1960): Anterior Extraperitoneal Lumbar Disk Excision and Vertebral Body Fusion. Clinical Orthopaedics, 18, 169.

Hastings, D. E. (1969): A Simple Frame for Operations on the Lumbar Spine. The Canadian Journal of Surgery, $12,251$.

Laurin, C. A., Migneault, G., Brunet, J. L., and Roy, P. (1969): Knee-Chest Support for Lumbosacral Operations. Canadian Journal of Surgery, 12, 245.

McElRoy, K. (1961): Lumbosacral Fusion by Bilateral Lateral Technique. Journal of Bone and Joint Surgery, 43-A, 918

Pennal, G. F., McDonald, G. A., and Dale, G. G. (1964): A Method of Spinal Fusion Using Internal Fixation. Clinical Orthopaedics and Related Research, 35, 86.

Relton, J. E. S., and Hall, J. E. (1967): An Operation Frame for Spinal Fusion. Journal of Bone and Joint Surgery, 49-B, 327.

Summersmith, G. (1969): Personal communication.

Thompson, W. A. L., and Ralston, E. L. (1949): Pseudarthrosis Following Spine Fusion. Journal of Bone and Joint Surgery, 31-A, 400.

Truchly, G., and Thompson, W. A. L. (1962): Posterolateral Fusion of the Lumbosacral Spine. Journal of Bone and Joint Surgery, 44-A, 505.

Watkins, M. B. (1953): Posterolateral Fusion of the Lumbar and Lumbosacral Spine. Journal of Bone and Joint Surgery, 35-A, 1014.

Wiltse, L. L., Bateman, J. G., and Duey, R. (1962): Experiences with Transverse Process Fusions in the Lumbar Spine. Journal of Bone and Joint Surgery, 44-A, 1013. 